\title{
Elaboração de geleias a partir de mișturas binárias compostas pelas polpas de laranja e acerola
}

\author{
Fruit jellies preparation from orange and acerola pulps
}

\author{
Daniela Helena Guimarães Pelegrine ${ }^{* 1}$, Marcela Soares Andrade ${ }^{2}$ e Suelen Heringer Nunes ${ }^{3}$ \\ ${ }^{1}$ Departamento de Engenharia Química , Escola de Engenharia de Lorena (EEL/USP), Brasil \\ ${ }^{2}$ Departamento de Ciências Agrárias , Universidade de Taubaté, Brasil \\ ${ }^{3}$ Departamento de Ciências Agrárias Universidade de Taubaté, Brasil
}

\begin{abstract}
Resumo
O presente trabalho teve como objetivo desenvolver formulações de geleia a partir das polpas de laranja e acerola, em diferentes proporções (F1: 50\% laranja e 50\% acerola; F2: 25\% laranja e 75\% acerola; F3: 75\% laranja e 25\% acerola). Tanto as polpas quanto o produto acabado, foram analisados com relação aos seguintes parâmetros físicoquímicos: $p H$, teor de sólidos solúveis totais, acidez titulável, umidade, atividade de água e teor de Vitamina C. A geleia foi processada em tacho a vapor de aço inoxidável, usando-se uma proporção de polpa: açúcar de 3:2 e, com relação à pectina ATM esta foi adicionada à mistura na proporção de 1,0\% da quantidade da polpa, conforme indicações do Senai (2006). Paralelamente às análises físicas e químicas, foram realizados testes sensoriais de aceitação e intenção de compra, onde os atributos aparência, cor, sabor e textura foram avaliados por testes afetivos através de uma escala hedônica de nove pontos, cujos resultados foram submetidos à avaliação estatística (ANOVA), ao nível 5\% de significância, mostrando que, apesar da maior preferência pela F2, não houve diferenças significativas entre as três formulações para os parâmetros aparência, sabor e textura. Com relação à cor, a F2 apresentou diferença significativa das demais.
\end{abstract}

Palavras-chave: Frutas cítricas. Produtos derivados. Análise sensorial.

\begin{abstract}
The proposal of present research includes to develop jellies formulations from orange and acerola pulps in different ratios (F1: $50 \%$ Orange and 50\% acerola; F2: $25 \%$ Orange and 75\% acerola; F3: $75 \%$ Orange and $25 \%$ acerolas). As the pulps as jellies were analysed respecting following physical and chemical parameters: $p H$, water activity, total soluble solids, acidity, moisture, and vitamin $C$ content. The jelly was prepared in stainless steel boiler, using pulp/sugar in 3/2 proportion. ATM pectin was added in 1\% pulp content, according Senai (2006). Besides physical-chemical analyses, acceptance and purchase intent sensory tests were performed where appearance, color, flavor and texture were evaluated through nine-point hedonic scale affective tests; the results were submitted to $5 \%$ (ANOVA) and showed that, despite the major preference by F2, there were no significant differences among the three formulations respecting appearance, taste and texture. Respecting color, F2 differed from the others.
\end{abstract}

Keywords: Citric fruits. Derived products. Sensory analysis. 


\section{Introdução:}

A fruticultura brasileira, direcionada para os mercados interno e externo, nos últimos anos, tem proporcionado ao país negócios que envolvem alguns milhões de dólares, milhares de empregos, inclusão social de homens e mulheres ao longo da cadeia produtiva, aproveitando-se de cenário mercadológico altamente promissor (Antunes, 2006: Hoffman and Antunes, 2007).

O Brasil é um dos três maiores produtores de frutas do mundo, sendo estas frutas cultivadas numa área aproximada de 2,2 milhões de hectares. Sua produção superou 43 milhões de toneladas em 2008, o que representa 5\% da produção mundial. Com esse saldo, o país fica atrás apenas da China e da Índia (Fachinello \& Nachtuigal, 2010; Andrade, 2012).

Dentro da fruticultura brasileira as frutas cítricas, nas últimas décadas, ocuparam posição de destaque nas exportações brasileiras de frutas frescas, correspondendo a US\$ 28 milhões com um extraordinário crescimento de 44,2\% em relação ao ano de 1998 (Senna et al, 2007).

Dentre as frutas cítricas, a laranja (Citrus sinensis) destaca-se, principalmente devido à sua participação no mercado internacional. Com relação às exportações de frutas processadas, a laranja corresponde a $90 \%$ deste total, sendo o Brasil maior fornecedor do mundo. (Santos et al., 2013).

Segundo Andrade (2012) a laranja é a principal fruta produzida no Brasil, com 18,1 milhões de toneladas saídas dos pomares em 2010, e responde por $42,9 \%$ do volume total da Fruticultura, um acréscimo na produção em 2,7 \% em relação a 2009. O estado de São Paulo é o principal produtor, com 13,9 milhões de toneladas, cuja participação representa $76,6 \%$ do volume.

Outra fruta que tem despertado grande interesse, por parte da população, é a acerola (Malpiglia glabra), muito utilizada no enriquecimento de sucos e alimentos dietéticos, devido à elevada concentração de ácido ascórbico (vitamina C), contendo ainda vitaminas A, B1, B2, B3, cálcio, fósforo e ferro (Adriano \& Leonel, 2012). Em relação ao teor de vitamina $C$, a acerola apresenta um teor entre 30 a 50 vezes maior do que o encontrado nas laranjas, implicando que 1 a 2 frutos de acerola são suficientes para suprir o requerimento humano diário dessa vitamina. Devido aos benefícios do consumo da acerola à saúde humana, esta tem sido largamente utilizada no enriquecimento nutricional de alimentos, ou mesmo de outros sucos, na última década (Carvalho et al, 2000; Nogueira et al., 2002; Cunha Neto, 2012).

No enriquecimento nutricional da polpa de laranja, esta pode ser misturada com a acerola, proporcionando um refrescante e agradável sabor, além de ser rica em vitamina C. Este tipo de polpa é muito bem aceito pelo fato de proporcionar um agradável paladar (Adriano \& Leonel, 2012).

Tanto a laranja quanto a acerola podem ser utilizados para consumo in natura ou então, na tentativa de reduzir os desperdícios resultantes da grande perecibilidade das mesmas, na produção de geleificados e doces caseiros sendo a geleia uma das de maior importância comercial, pois, além de preservar grande parte de suas propriedades, trata-se de um produto que não necessita de insumos químicos, além de ser apreciado por todo o mundo (Kluge et al, 2006; Machado et al, 2006; Lago et al., 2006; Antunes, 2007; Pelegrine et al, 2012).

Devido ao exposto acima, o presente trabalho teve como objetivo a elaboração de três formulações de geleia de laranja enriquecida com acerola, a partir da polpa destas duas frutas, em diferentes proporções, assim como analisar os atributos sensoriais do produto final, de modo a verificar diferenças significativas, com relação ao sabor, cor, aroma e textura.

Em ciência e tecnologia de alimentos, testes sensoriais de diferença são utilizados para detectar diferenças sensoriais que possam advir de alterações químicas ou físicas que sofreram diferentes tratamentos. Assim, diferenças nas propriedades sensoriais dos alimentos podem originar-se de variações nas formulações e processamento dos alimentos. $\mathrm{Na}$ análise sensorial, recomenda-se uma equipe composta por 30 a 50 provadores (Stone \& Sidel, 1993; Meilgaard et al., 1999).

\section{Material e Métodos:}

Para o preparo da geleia, foram utilizados frutos de laranja (Variedade Pera) e acerola (variedade cereja) adquiridos em supermercados localizados no município de Taubaté. As frutas foram então selecionadas levando em consideração a aparência (danos mecânicos), amadurecimento e senescência, perda de água e podridões. A seguir, a matéria prima selecionada foi muito bem lavada com solução de água clorada, descascada e desprovidas das sementes. A seguir, procedeu-se com o despolpamento das frutas em despolpadeira (marca Makanuda, modelo DM-Ci-SP) com tela de 1,6 mm de abertura, visando a um máximo rendimento na extração da polpa.

Para a caracterização da polpa as análises físico-químicas foram realizadas: $\mathrm{pH}$ (A.O.A.C., 1980 - Method 16192); teor de sólidos solúveis totais (Adolfo Lutz, 315/IV); teor de Vitamina C (Lima et al., 2003) e teor de Umidade (Adolfo Lutz, 309/IV).

Em seguida, a geleia foi processada em tacho a vapor de aço inoxidável (marca Kromodinâmica) com agitação contínua. Para o processamento da geleia, utilizou-se a proporção polpa: açúcar de 3:2. Com relação à pectina ATM, esta foi adicionada à mistura na proporção de $1,0 \%$ da quantidade da polpa, conforme indicações do Senai (2006). A polpa já adicionada de $30 \%$ da quantidade total da sacarose foi aquecida até atingir um teor de sólidos solúveis correspondente a $35^{\circ} \mathrm{Brix}$. Uma vez atingida tal consistência, o restante do açúcar junta- 
mente com a pectina já hidratada (na proporção de 150 gramas de água para cada 8 gramas de pectina), foram adicionados, sendo a mistura mantida sob aquecimento até concentração final de sólidos solúveis de $67^{\circ}$ Brix.

Com relação às polpas, estas foram constituídas por misturas binárias das polpas de laranja e acerola em diferentes porções, da seguinte maneira:

F1: $50 \%$ de polpa de laranja e 50\% de polpa de acerola;

F2: $25 \%$ de polpa de laranja e 75\% de polpa de acerola

F3: $75 \%$ de polpa de laranja e $25 \%$ de polpa de acerola

Após processada, a geleia foi envasada a quente, em embalagens de vidro com capacidade para $250 \mathrm{~g}$, fechadas com tampa de metal (previamente higienizadas) invertidas por 15 minutos e posteriormente resfriadas por água fria; e estocadas à temperatura ambiente.

O produto acabado foi então analisado com relação aos seguintes parâmetros físico-químicos: $\mathrm{pH}$ (A.O.A.C., 1980 - Method 16192); teor de sólidos solúveis totais (Adolfo Lutz, 315/IV); acidez titulável (Adolfo Lutz, 310/IV); teor de umidade (Adolfo Lutz, 309/IV); teor de Vitamina C (LIMA et.a l, 2003) e Atividade de água, utilizando equipamento medidor da atividade de água.

\section{Análise Sensorial}

Paralelamente às análises físicas e químicas, foram realizados testes sensoriais de aceitação e intenção de compra da geleia por uma equipe não treinada de 50 julgadores. Os atributos aparência, cor, sabor e textura foram avaliados por testes afetivos através de uma escala hedônica de nove pontos. As amostras foram servidas em porções de $15 \mathrm{~g}$, em pratos brancos codificados com algarismos de três dígitos aleatórios, sendo a ordem de apresentação devidamente balanceada.

As três formulações de geleia de alranja com acerola foram então submetidas a testes sensoriais de aceitabilidade, onde cada provador recebeu, juntamente com as amostras de geleia uma ficha de avaliação que contém 9 faces correspondendo respectivamente a 9 (gostei extremamente), 8 (gostei muito), 7 (gostei moderadamente), 6 (gostei ligeiramente), 5 (não gostei nem desgostei), 4 (desgostei ligeiramente), 3 (desgostei moderadamente), 2 (desgostei muito) e 1 (desgostei extremamente).

Além do teste de aceitação, anteriormente descrito, foi realizado o além do teste de intenção de compra, o qual conteve 5 faces, correspondendo, respectivamente a 5 (certamente compraria), 4 (possivelmente compraria), 3 (talvez compraria / não compraria), 2 (possivelmente não compraria) e 1 (certamente não compraria).

Os resultados da análise sensorial foram submetidos analise de variância (Anova) e as médias comparadas pelo teste de Tukey ao nível 5\%.

\section{Resultados e Discussão:}

As análises referentes à caracterização das polpas de laranja e acerola foram todas realizadas em triplicata, para verificar se há divergência de resultados nas repetições.

Tabela 1: Propriedades físico-químicas das polpas de laranja e acerola e das misturas binárias.

\begin{tabular}{|c|c|c|c|c|c|}
\hline & $\mathrm{PH}$ & $\begin{array}{l}\text { SÓLIDOS } \\
\text { SOLÚVEIS } \\
\left({ }^{\circ} \text { BRIX) }\right.\end{array}$ & $\begin{array}{l}\text { UMIDADE } \\
(\%)\end{array}$ & $\begin{array}{c}\text { ÁCIDO } \\
\text { ASCÓRBICO } \\
\text { (MG/100 ML) }\end{array}$ & $\begin{array}{l}\text { ATIVIDA } \\
\text { DE ÁGUA }\end{array}$ \\
\hline $\begin{array}{l}\text { POLPA DE } \\
\text { LARANJA }\end{array}$ & $\begin{array}{c}3,75 \\
(0,02)\end{array}$ & $8,20(0,00)$ & $\begin{array}{l}91,92 \\
(1,03)\end{array}$ & $\begin{array}{l}31,75 \\
(0,13)\end{array}$ & -- \\
\hline $\begin{array}{l}\text { POLPA DE } \\
\text { ACEROLA }\end{array}$ & $\begin{array}{c}3,49 \\
(0,03)\end{array}$ & $7,00(0,00)$ & $\begin{array}{l}92,66 \\
(2,31)\end{array}$ & $\begin{array}{c}1324,00 \\
(1,26)\end{array}$ & -- \\
\hline M.1 & $\begin{array}{c}4,36 \\
(0,00)\end{array}$ & $7,20(0,00)$ & $\begin{array}{l}91,34 \\
(0,12)\end{array}$ & $\begin{array}{c}1674,00 \\
(0,42)\end{array}$ & -- \\
\hline M.2 & $\begin{array}{c}3,33 \\
(0,07)\end{array}$ & $7,00(0,00)$ & $\begin{array}{l}93,68 \\
(2,01)\end{array}$ & $\begin{array}{c}1839,24 \\
(2,21)\end{array}$ & -- \\
\hline M.3 & $\begin{array}{c}4,16 \\
(0,03)\end{array}$ & $\begin{array}{c}7,80 \\
(0,00)\end{array}$ & $\begin{array}{l}94,27 \\
(1,97)\end{array}$ & $\begin{array}{c}1243,75 \\
(1,43)\end{array}$ & \\
\hline F.1 & $\begin{array}{c}2,93 \\
(0,05)\end{array}$ & $\begin{array}{l}70,68 \\
(0,00)\end{array}$ & -- & $\begin{array}{c}1342,31 \\
(2,52)\end{array}$ & $\begin{array}{l}0,789 \\
(0,13)\end{array}$ \\
\hline F. 2 & $\begin{array}{c}3,24 \\
(0,00)\end{array}$ & $\begin{array}{l}68,06 \\
(0,00)\end{array}$ & -- & $\begin{array}{c}1848,03 \\
(4,25)\end{array}$ & $\begin{array}{l}0,831 \\
(0,02)\end{array}$ \\
\hline F. 3 & $\begin{array}{c}2,8 \\
(0,03)\end{array}$ & $\begin{array}{l}71,78 \\
(0,00)\end{array}$ & -- & $\begin{array}{r}873,57 \\
(8,62)\end{array}$ & $\begin{array}{l}0,801 \\
(0,16)\end{array}$ \\
\hline
\end{tabular}

M1: mistura binária (50\% polpa de acerola e 50\% polpa de laranja); M2: mistura binária (75\% polpa de acerola e 25\% polpa de laranja); M3: mistura binária (75\% polpa de laranja e 25\% polpa de acerola); F1: Geleia elaborada a partir da M1; F2: Geleia elaborada a partir da M2; F3: Geleia elaborada a partir da M3. 
Os lotes dos produtos que foram utilizados na elaboração da geleia apresentaram composição centesimal características de cada produto, cujos resultados resumem-se nas Tabelas 1, sendo que cada valor representa a média das três repetições referente a cada análise, para cada produto.

Com relação aos resultados expressos na Tabela1, verifica-se que a polpa de laranja utilizada no processamento da geleia apresentou composição centesimal características de cada produto, conforme resultados obtidos na literatura (Asenjo, 1980; Araujo, 1994; Fialho et al., 2007). Com relação à polpa de acerola, ainda que os teores de Sólidos Solúveis Totais e acidez Total Titulável encontrados na acerola estão bem próximos aos citados por Melo et al (1999), o teor de Vitamina C foi inferior ao encontrado pelos autores. Tal discrepância pode ser justificada pela influência de certos fatores da fruta, tais como o grau de maturação, as condições climáticas e edáficas locais, índice de pluviosidade, características do solo, dentre outros.
Ainda com relação aos resultados apresentados na Tabela 1, verifica-se que o teor de vitamina $C$ da geleia F2 mostrou-se mais elevado que nas demais, visto que nesta formulação a proporção de suco de acerola (que apresenta teor de vitamina C superior ao da laranja), foi superior. Por ouro lado, a quantidade de vitamina $C$ retida no produto foi bastante significativa, para as três formulações, o que pode-se afirmar que a geleia de frutas cítricas podem ser consideradas excelentes fontes de vitamina $C$.

Os resultados da análise sensorial, avaliados a partir de dados estatísticos para as formulações de geleia de laranja enriquecida com acerola são mostrados na Tabela 2, juntamente com o histograma referente à intenção de compra do produto (Figura 1).

Com relação aos resultados acima apresentados na tabela 2 observa-se que, apesar da maior preferência pela formulação F2 para todos os atributos, não houve diferenças significativas entre as três formulações para os parâmetros aparência, sabor e textura. Com relação

Tabela 2: Tabela dos resultados da análise sensorial.

\begin{tabular}{lllll}
\hline Amostra & Cor & Aparência & Sabor & Textura \\
\hline F1 & $7,625^{a}$ & $7,809^{a}$ & $7,587^{a}$ & $7,756^{a}$ \\
F2 & $8,333^{a}$ & $7,894^{a}$ & $7,783^{a}$ & $7,822^{a}$ \\
F3 & $7,438^{a}$ & $7,468^{a}$ & $7,565^{a}$ & $7,467^{a}$
\end{tabular}

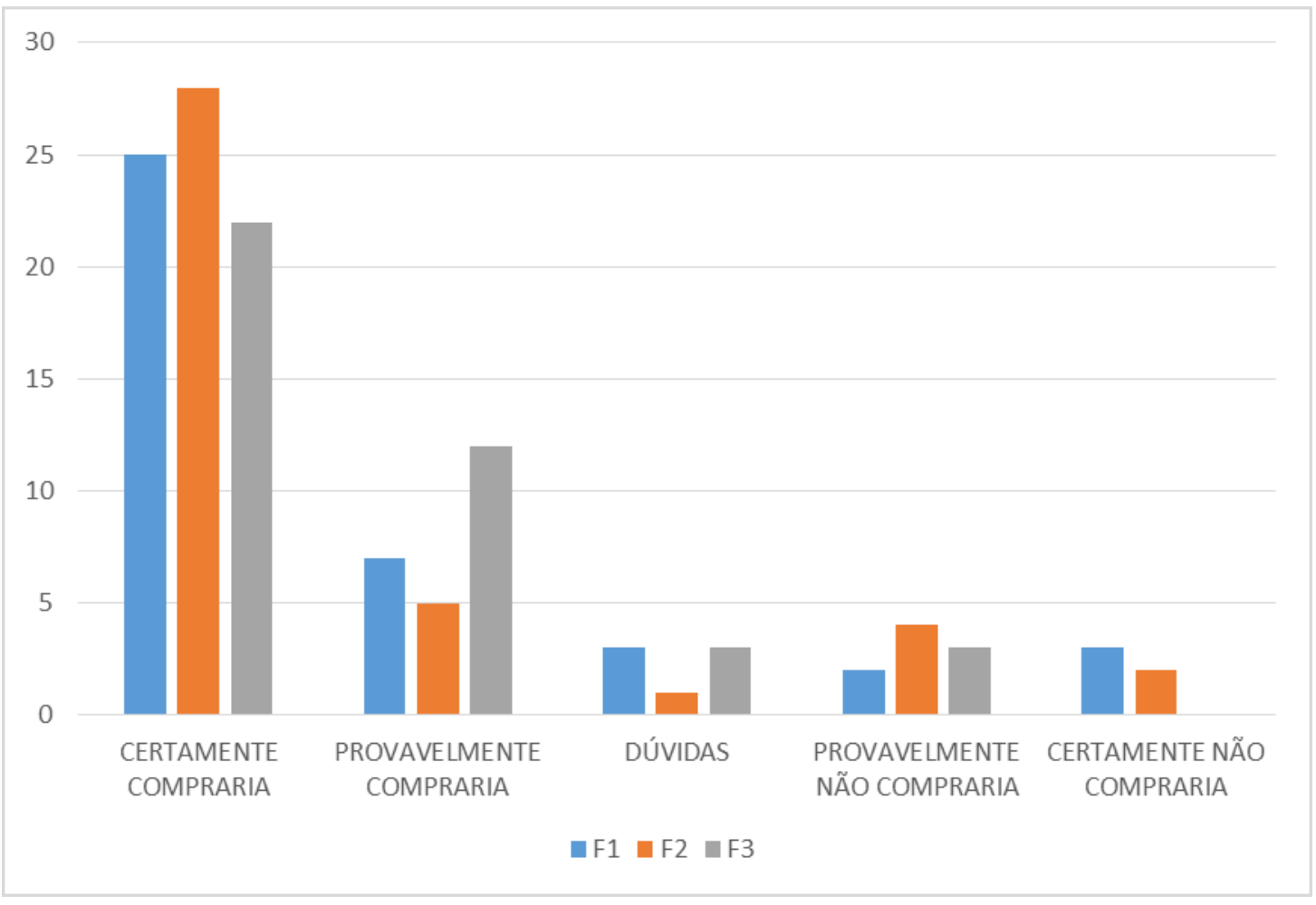

Figura 1: Teste de intenção de compra das diferentes formulações de geleia de amora. 
ao atributo cor, a formulação F2 apresenta diferença significativa das demais.

Ainda com relação aos resultados apresentados na Tabela 2, observa-se que o enriquecimento nutricional da geleia de laranja por meio do acréscimo da polpa de acerola torna-se uma alternativa viável, visto que tais resultados parecem mais favoráveis, quanto maior a porcentagem da polpa de acerola na formulação da geleia. Além disto, a acerola trata-se de uma das frutas de maior queda de preço; de acordo com Lima (2013) dentre os produtos com preço em baixa, a queda no preço da acerola $(-23,91 \%)$ está mais pronunciada, quando comparada à da laranja (-2,3\%), o que viabiliza, economicamente, o acréscimo da acerola em doces, sucos e geleias de laranja.

A partir dos resultados expressos na Figura 1, um ponto de destaque é que, para todas as formulações, os resultados convergem para a esquerda, indicando boa aceitação das mesmas.

\section{Conclusão:}

Dos resultados apresentados no item anterior, podese concluir que:

1. A formulação F2 (geleia preparada a partir da mistura binária constituída por $75 \%$ de polpa de acerola e $25 \%$ de polpa de laranja) foi a preferida, com relação a todos os atributos;

2. Todas as formulações desenvolvidas tiveram notas bastante próximas entre si, nos atributos sabor, textura e aparência;

3. Apenas com relação ao atributo cor a formulação F2 apresentou diferença significativa perante as demais.

\section{Rererências:}

A.O.A.C. Official Methods of Analysis. Washington: Sidney Willians, 1980. 1141p.

ADRIANO, E.; LEONEL, S. Fenologia da aceroleira cv. Olivier em Junqueirópolis-SP. Revista Brasileira de Fruticultura, vol.34, n.2, pp. 469-474, 2012.

ANDRADE, P.F.S. Fruticultura: Análise da conjuntura agropecuária Safra 2011/12.

Secretaria da Agricultura e do Abastecimento do Estado do Paraná. 2012.

ANTUNES, L.E.C. Amora-preta: nova opção de cultivo no Brasil. Ciência Rural, v. 32, n. 1, p. 151-158, 2002.
ASENJO, C.F. Acerola. In: NAGY, S.; SHAW, P.E. (Ed.). Tropical and subtropical fruits: composition, properties and uses. Westport : AVI, 1980. p.341-374.

BLIGH, E. G.; DYER, W. J. A rapid method of total lipid extraction and purification. Canadian. Journal of of Biochememical and Physiology,v.37, p.911-917, 1959.

BOTEON, M. Mercado interno de frutas cítricas. 2000. 86 f. Dissertação (Mestrado) - Escola Superior de Agricultura "Luís de Queiroz", Universidade de São Paulo, Piracicaba, 2000.

CARVALHO, R.A. Análise econômica da produção de acerola no município de Tomé-Açú, Pará. Belém: Embrapa Amazônia Oriental, 2000. 21p. (Documento, 49).

CUNHA NETO, T.; RABELO, M.C.; BERTINI, C.H.C.M.; MARQUES, G.V.; MIRANDA, M.R.A. Caracterização Agronômica e Potencial Antioxidante de frutos de clones de aceroleira. Revista Ciências Agronômicas, v.43, n.4, p. 713-721, 2012.

FACHINELLO, J.C.; NACHTIGAL, J.C. Situação da fruticultura no Brasil. In: Introdução a Fruticultura, cap.1. Embrapa, 2010.

FIALHO,L E. et al. Estabilidades química, físico-química e microbiológica de suco de laranja cv. "Pêra" submetido a diferentescondições de estocagem. Revista Boletim Centro de Pequisa de Processamento de Alimentos, v.25, n.2, p. 235-246, 2007.

INSTITUTO ADOLFO LUTZ. Normas Analíticas do IAL: Métodos químicos para análise de alimentos. 4. ed. São Paulo, 2005. 1018 p.

KLUGE, R.A., HOFFMANN, A., BILHALVA, A.B. Comportamento de frutos de mirtilo (Vaccinium ashei Reade) cv. Powder Blue em armazenamento refrigerado. Ciência Rural, v.24, n.2, p. 281-285, 1994.

LAGO, E.S.; GOMES, E.; SILVA, R. Produção de geléia de jambolão (Syzygium cumini Lamarck): Processamento, Parâmetros físico-químicos e avaliação sensorial. Ciência e Tecnologia de Alimentos, v.26, n.4, p. 847-852, 2006.

LIMA, G. Feijão verde fica mais caro e acerola mais barata na última semana de maio. Disponível em http:// nominuto.com/noticias/economia/feijao-verde-ficamais-caro-e-acerola-mais-barata-na-ultima-semanade-maio/85524/. 
MACHADO, N. P.; FRANCHINI, E. R.; RISTOW, N. C.; COUTINHO, E. F. CANTILLANO, F. R. F.; MALGARIM, M. B. Conservação pós-colheita de mirtilos 'Florida', 'Woodard' e 'Bluegem' em atmosfera com oxigênio ionizado. Toda Fruta, 12 jun. 2006. Disponível em: <http://www.todafruta.com.br/ mostraconteudo.asp? conteudo $=12701>$. Acesso em: 08 ago. 2006, 11:22:06.

MELO, E.A.; LIMA, V.L.A.G.; NASCIMENTO, P.B. Formulação e avaliação físico-química e sensorial de geleia mista de pitanga e acerola. Boletim Ceppa, v.17, n.1, p.33-44, 1999.

PELEGRINE, D.H.G. ; ALVES, G. L. ; QUERIDO, A. F. ; CARVALHO, J. G. . Geléia de mirtilo elaborada com frutas da variedade Climax. Revista Brasileira de Produtos Agroindustriais, v. 14, p. 225-231, 2012.

SENNA, Ana Júlia Teixeira; PEDROZO, Eugenio Ávila and KOLLER, Otto Carlos. Identificação e análise da cadeia de distribuição das frutas cítricas de mesa sem sementes: um estudo de caso na cidade de São Paulo. Revista Brasileira de Fruticultura, vol.29, n.3, pp. 508-512, 2007.

NOGUEIRA, R. J. M. C.; MORAES, J. A. P. V.; BURITY, H. A.; SILVA JÚNIOR, J. F. Efeito do estádio de maturação dos frutos nas características físico-químicas de acerola. Pesquisa Agropecuária Brasileira, Brasília, v. 37, n. 4, p. 463-470, 2002.

SANTOS, R. M.; NAAS, I. A.; MOLLO NETO, M.; VENDRAMETTO, O. An overview on the Brazilian orange juice production chain. Revista Brasileira de Fruticultura, vol.35, n.1, pp. 218-225, 2013. 